\title{
Application of Fuzzy Logic Algorithm for Hybrid Car Usage Time
}

\author{
Ronny Katuuk \\ Department of Computer \\ Engineering \\ Manado State Polytechnic
}

\author{
Marson James Budiman \\ Department of Computer \\ Engineering \\ Manado State Polytechnic
}

\author{
Donald B. Noya \\ Department of Electrical \\ Engineering \\ Manado State Polytechnic
}

\begin{abstract}
Electricity generating systems in motorized vehicles use motor rotation with gasoline or diesel fuel to supply voltage to electronic devices and batteries as a backup power source.A good battery performance, will support the device that is supported while the amount of energy that can be stored by the battery is limited, the battery will experience a charge and discharge cycle. Therefore, there must be continuous battery charging needed so that the battery erformance can reach the maximum. One solution to developing the hybrid method in charging batteries is to utilize two sources of electricity, namely charging from the vehicle engine and wind power plants that are obtained when the vehicle is running. The method used is the fuzzy logic method by assessing the input and output system from the observations. In this research will be carried out the design of hybrid power plants for the use of load with time simulation to supply the load in order to obtain accurate battery usage time modeling so as to make the battery not quickly damaged. The results of the hybrid generator design on four-wheeled motor vehicles can maintain the source of electricity in the battery and use fuel efficiently.
\end{abstract}

\section{Keywords}

Battery, hybrid power plant, discharging

\section{INTRODUCTION}

Understanding hybrid car technology is a car that combines engines using fuel oil and engines with motor drives using battery power [6]. There are several objectives of Hybrid car technology, such as fuel-efficient cars, increased car power and additional power for the addition of devices that use electrical power in cars, such as audio [6]. There are currently two types of Hybrid cars, Hybrid standard and full Hybrid[6].

The high price of fuel oil has made car manufacturers compete to make fuel efficient cars. Of course, a fuel efficient car then reduces vehicle performance will not be liked by most consumers. Therefore, car manufacturers make Hybrid car technology or called the Hybrida car. Wind energy is energy that is wasted when the car is running, if the wind energy is used as additional energy to supply to the battery it will further stimulate the use of car fuel. in this study will be designed hybrid power plant control by combining the energy generated from engine speed and wind energy to supply batteries.

\section{METHODOLOGY}

\subsection{Stages - Stages of Research}

The research stages that will be carried out include data collection, hardware design and software design, system testing using matlab software simulation based on fuzzy logic

[1][4][7]. In full, the stages of this research are described as a whole in the research flow chart shown in Fig. 1 along with indicators of achievement success.[2][9]

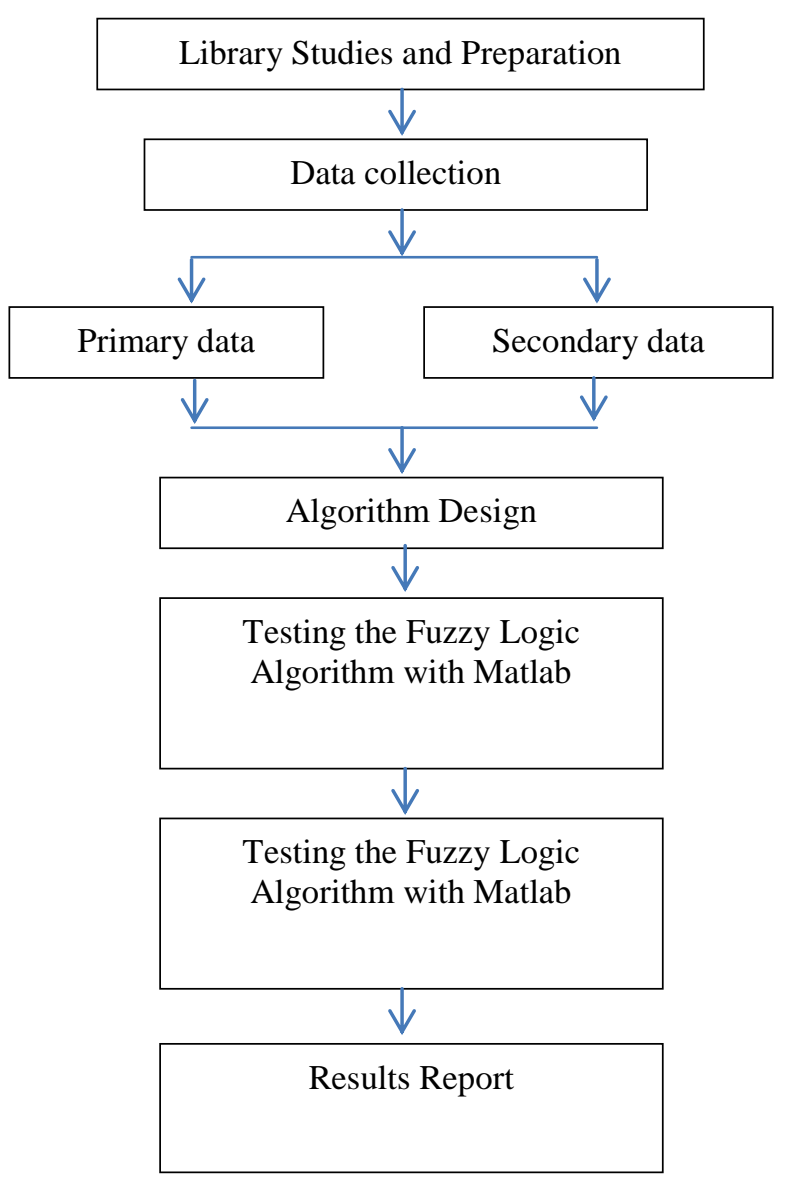

Fig 1: Research Flow Chart

\subsection{Performance Indicators}

Table 1. Table Indicators of achievement of research results

\begin{tabular}{|c|l|l|l|}
\hline Stages & $\begin{array}{c}\text { Details of } \\
\text { activities }\end{array}$ & \multicolumn{1}{|c|}{$\begin{array}{c}\text { Research } \\
\text { Activities }\end{array}$} & $\begin{array}{c}\text { Achievement } \\
\text { Idicator }\end{array}$ \\
\hline Literature & Study & Library search & From the \\
\hline
\end{tabular}




\begin{tabular}{|c|c|c|c|}
\hline review. & $\begin{array}{l}\text { library of } \\
\text { the system } \\
\text { that will } \\
\text { be made. }\end{array}$ & $\begin{array}{l}\text { about the system } \\
\text { to be created }\end{array}$ & $\begin{array}{l}\text { results } \\
\text { search } \\
\text { obtained data } \\
\text { reference as } \\
\text { reference to } \\
\text { research. }\end{array}$ \\
\hline $\begin{array}{l}\text { Design } \\
\text { and } \\
\text { manufact } \\
\text { ure }\end{array}$ & $\begin{array}{l}\text { Software } \\
\text { Design. }\end{array}$ & $\begin{array}{l}\text { Designing an } \\
\text { interface device } \\
\text { for the Fuzzi } \\
\text { Logic Algorithm. }\end{array}$ & $\begin{array}{l}\text { Generate } \\
\text { circuit } \\
\text { schemes and } \\
\text { diagrams for } \\
\text { software } \\
\text { design }\end{array}$ \\
\hline Testing & $\begin{array}{l}\text { Testing } \\
\text { the system } \\
\text { with a } \\
\text { simulation } \\
\text { program } \\
\text { Laborator } \\
y \quad \text { testing } \\
\text { of } \\
\text { applicatio } \\
n \text { systems }\end{array}$ & $\begin{array}{l}\text { Test the system } \\
\text { with a simulation } \\
\text { program } \\
\text { Conduct } \\
\text { laboratory tests to } \\
\text { obtain data in } \\
\text { accordance with } \\
\text { system } \\
\text { applications. }\end{array}$ & $\begin{array}{l}\text { Generate } \\
\text { simulation } \\
\text { system tes } \\
\text { results } \\
\text { Obtain data } \\
\text { that matches } \\
\text { the system } \\
\text { application }\end{array}$ \\
\hline
\end{tabular}

\section{RESULTS AND DISCUSSION}

\subsection{Fuzzy Logic Testing}

After the programming is complete, it is tested to find out whether the program was made successful or not.[1][3][9] This test uses MATLAB simulation with Fuzzy Logic[2][10]. From the test it was found that the program managed to run well with the program [12][15]flow as shown in the following Fig.2:

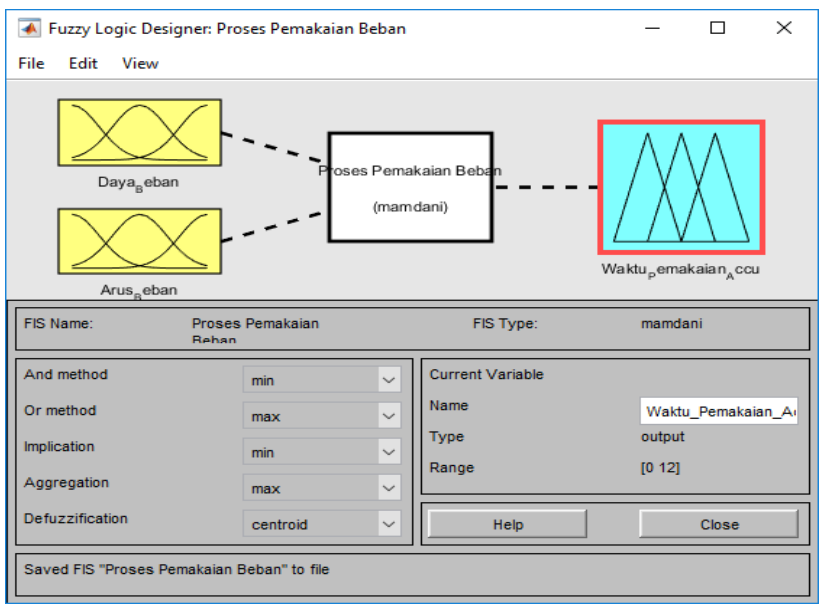

Fig 2: Input design and system output

The system is designed with two inputs and one output[12][13]. The input made in five parts in the membership function for input usage is load;

- Very less

- Somewhat less

- Medium

- A bit big
- Hugh

The load usage input is shown in the membership design function Fig. 3.[15][17]

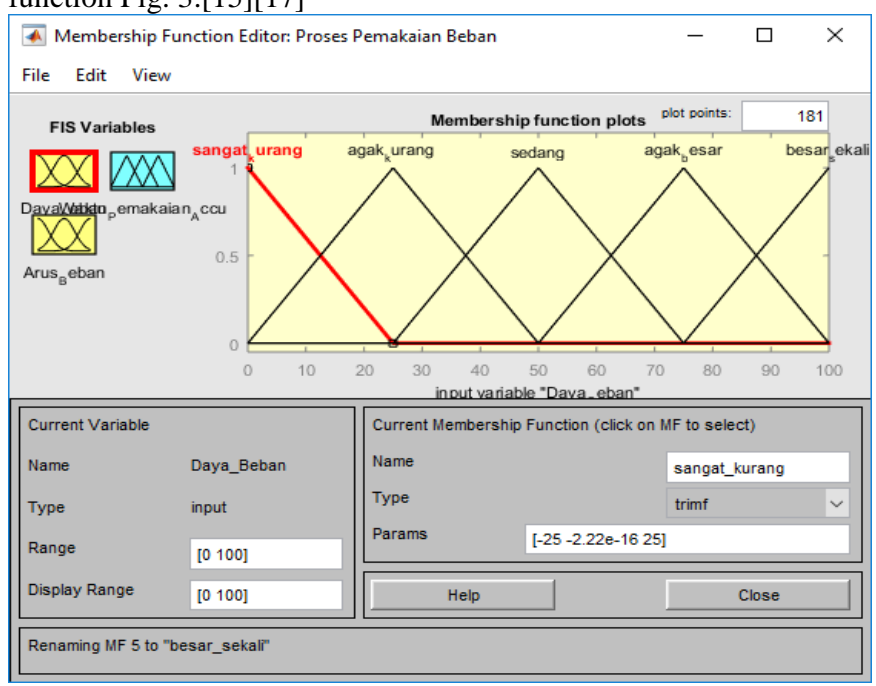

Fig 3: Membership design is the power consumption input function

For membership functions for input Load current is the same as the membership load usage function of fig.4 [14] [6]

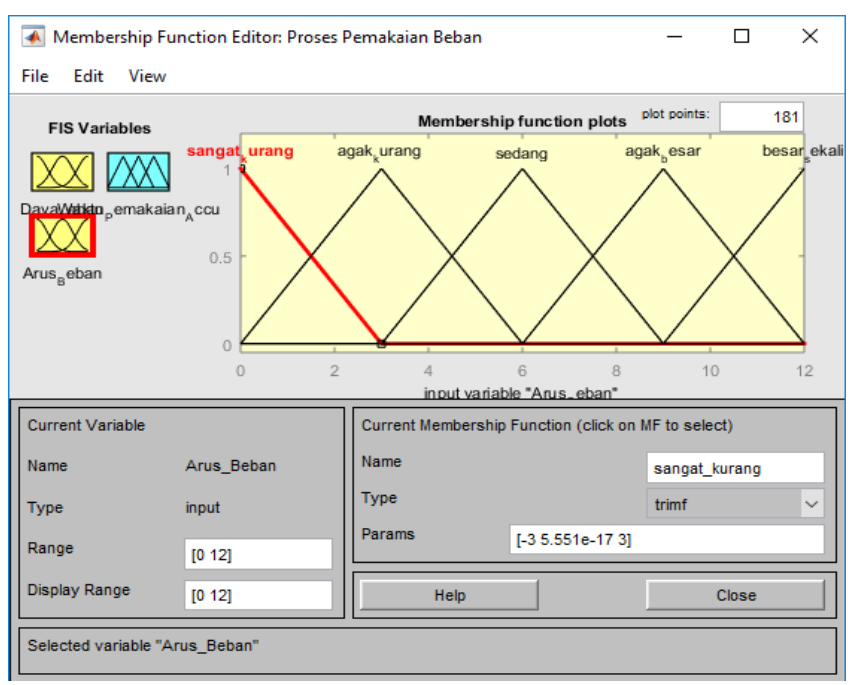

Fig 4: Membership design input function Load current

[14][16[17]For membership functions for Output battery usage time is;

- Very slow

- Slow

- Hurry up

- A little fast

- Very fast [1][17]

The chat area input shown in the membership design function Fig.5. 


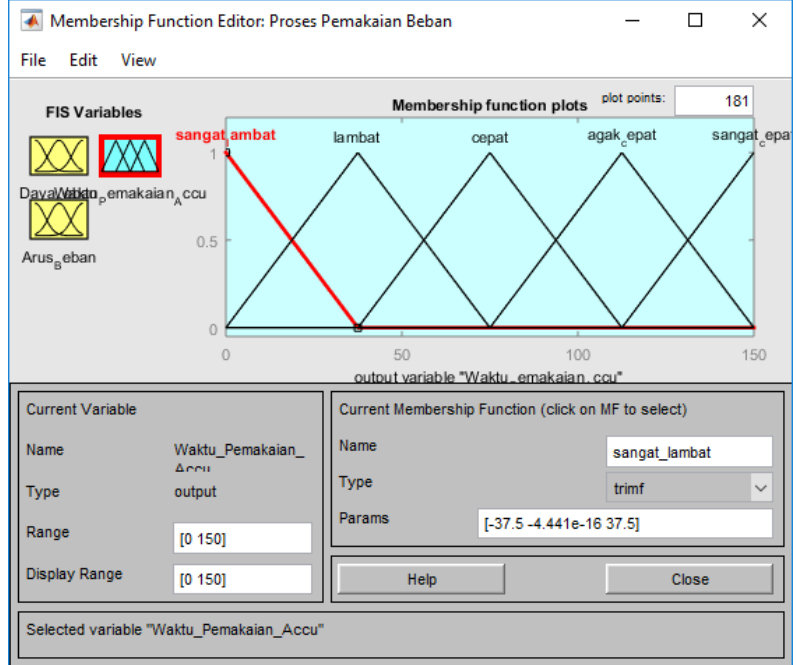

Fig 5: Membership design Output function of battery usage time

After the design of each part of the input and output, the next step is to make a rule for each condition that will occur [2][5]. Fig.6.

A Rule Editor: Proses Pemakaian Beban

$\square \times$

File Edit View Options

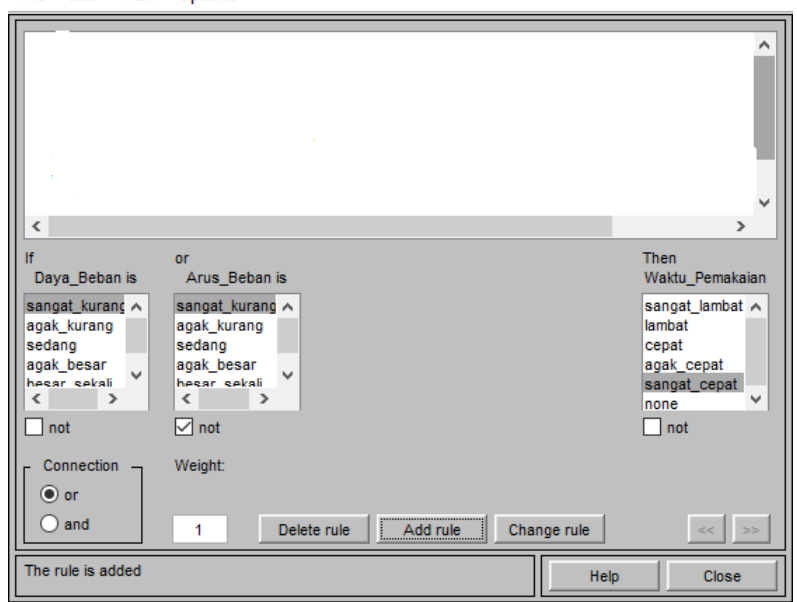

Fig 6: Rule placement for each load usage condition

From each of the five input and output conditions, each of the possibilities that occur will be described[3][4]. From the design of loading conditions to output the battery usage time is obtained by 12 possibilities using a cryptic logic algorithm[11][14]. The process of filling every possible rule is when the rule is activated, there will be three menus of two input parameters and one output parameter. [1][4] The rule filling is inputted with 12 possibilities with input load and current generated. View rule displays the input and output values resulting from the fuzzy logic process shown in Fig.8. with load data $=50$ watts, current $=6$ amperes and 7 hours battery usage time.

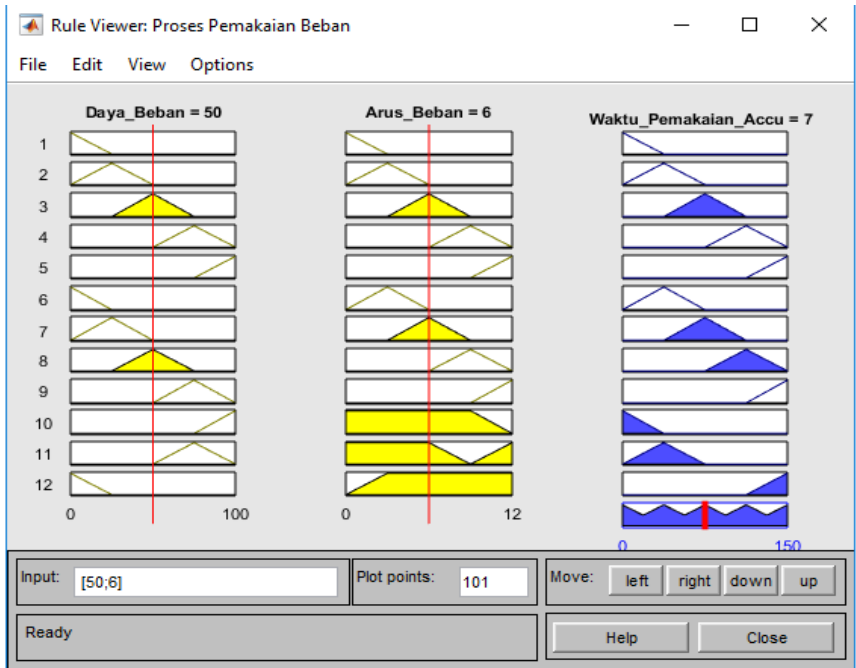

Fig 8: Rule filling

\subsection{Test results with calculations}

Obtained from the draft there are five testing scenarios; 1 . For a 50 watt load that will be supplied with a $12 \mathrm{v} / 50 \mathrm{Ah}$ battery then:

$>\mathrm{I}=\mathrm{p} /(\mathrm{V})=(50$ watts $) /(12 \mathrm{~V})=4,167$ Ampere

$>$ Charging time:

$50 \mathrm{Ah} / 4,167 \mathrm{~A}=11.99$ Hours

$>\quad$ Battery deficiency of $20 \%$ (2,398 hours)

Then: 11.99 - 2,398 = 9,592 hours

Usage time: 9 hours, 35 minutes, 31.2 seconds

For Fuzzy logic testing at 50 Ampere power obtained battery usage time of 7 hours there is a difference of 2 hours from the calculation[7][8][16].

The calculation table with different load power is shown in Table 2 .

Table 2. Table Test results with battery usage calculations

\begin{tabular}{|c|c|c|c|}
\hline No & $\begin{array}{c}\text { Power Load } \\
\text { (watts) }\end{array}$ & $\begin{array}{c}\text { Current } \\
\text { (Ampere) }\end{array}$ & $\begin{array}{c}\text { Battery usage } \\
\text { time (hours) }\end{array}$ \\
\hline 1 & 5 & 0,416 & $123: 47: 38,4$ \\
\hline 2 & 10 & 0,833 & $57: 37: 33,6$ \\
\hline 3 & 20 & 1,666 & $27: 36: 50,4$ \\
\hline 4 & 30 & 2,5 & $17: 36: 2,7$ \\
\hline 5 & 40 & 3,333 & $12: 36: 12,6$ \\
\hline 6 & 50 & 4,167 & $9: 35: 31,2$ \\
\hline 7 & 60 & 5 & $7: 36: 7,2$ \\
\hline 8 & 70 & 5,83 & $6: 10: 26,4$ \\
\hline 9 & 80 & 6,667 & $5: 6: 3,6$ \\
\hline 10 & 90 & 7,5 & $4: 16: 8,4$ \\
\hline 11 & 100 & 8,3 & $3: 36: 7,2$ \\
\hline
\end{tabular}




\section{CONCLUSIONS}

Based on the results of the research that has been done, the following points can be concluded:

The fuzzy method provides the right results in the simulation that has been done, with a membership function that describes the conditions of input and output. Forming the output value in the Fuzzy method can be formed based on the work description of the system that results in battery usage time. From the results of the application with the Fuzzy algorithm where the load value $=50$ watts, the current generated is 6 Ampere, this input results in battery usage time $=7$ hours

\section{ACKNOWLEDGMENTS}

Thanks to the Ministry of Research and Technology and Higher Education and manado state polythecnic, which has funded this research with competitive grants program in 2018 so as to do research and work well.

\section{REFERENCES}

[1] I K Mujawar, B T Jadhav and Kapil Patil. Web-based Fuzzy Expert System for Symptomatic Risk Assessment of Diabetes Mellitus. International Journal of Computer Applications 182(3):5-12, July 2018

[2] L.Doitsidis,K.P. Valavanis, N.c. Tsourveloudis, (2002). Fuzzy Logic Based Autonomonous Skid Steering Vehicle Navigation. Proceeding of the 2002 IEEE International Conference on Robotics \& Automation Washington, DC May 2002

[3] Ionescu F., Haszier F., 2000. "Comparison between classical and fuzzy-controller for electrohydraulic axes", International Symposium on Neuro-Fuzzy Systems, pp.155-160.

[4] Puneet Kumar, Nikhil Jindal, Akhil Jindal and Sidharth Chhabra. (2010). A Robust Algorithm for Local Obstacle Avoidance. International Journal of Computer Theory and Engineering.June, 2010

[5] Sourav Dutta. (2010). Obstacle Avoidance of mobile robot using PSO based Neuro Fuzzy Technique. International Journal on Computer Science and Engineering

[6] John Kwesi Amfo and James Ben Hayfron-Acquah. Modeling of Hybrid Intrusion Detection System in Internet of Things using Support Vector Machine and Decision Tree. International Journal of Computer Applications 181(15):45-52, September 2018

[7] Nour M.I.H, Ooi J. and Chan K.Y., 2007. "Fuzzy logic control vs. conventional PID control of an inverted pendulum robot",Proceedings of 2007 ICIAS International Conference on Intelligent and Advanced Systems,

[8] Ahmed Nasser B Alsammak. Fuzzy Logic based Power Factor Control of Synchronous Machine. International Journal of Computer Applications 182(14):33-42, September 2018

[9] Preeti Saroj and Sanjay Kumar. A Novel Power Efficient Clustering Technique with a Fault Tolerance Mechanism based on Type -2 Fuzzy Logic, in a Multi-hop WSN. International Journal of Computer Applications 181(5):59, July 2018.

[10] Surapati Pramanik, Indrani Maiti and Tarni Mandal. A Taylor Series based Fuzzy Mathematical Approach for Multi Objective Linear Fractional Programming Problem with Fuzzy Parameters. International Journal of Computer Applications 180(45):22-29, May 2018.

[11] Ahmed N. B. Al-Sammak, "A Fuzzy Logic Control of Synchronous Motor for Reactive Power Compensation", $\mathrm{PhD}$ thesis, University of Mosul, 2017.

[12] Sang-hyeok Lim and Tae-ho Cho. Automatic Threshold Reset Scheme using a Double Fuzzy System for Improvement of Detection Rate in a Probabilistic Voting-based Filtering Scheme of WSNs. International Journal of Computer Applications 176(1):38-43, October 2017.

[13] Syed Wajahat A Rizvi, Raees Ahmad Khan and Vivek Kumar Singh. Early Stage Software Reliability Modeling using Requirements and Object-Oriented Design Metrics: Fuzzy Logic Perspective. International Journal of Computer Applications 162(2):44-59, March 2017.

[14] Jaiswal, G.P. and Giri, R. N. 2015. A Fuzzy Inference Model for Reliability Estimation of Component Based Software System. International Journal of Computer Science and Technology, 3(3), 177-182.

[15] Rizvi, S.W.A., Singh, V. K., and Khan, R. A. 2016 Fuzzy Logic based Software Reliability Quantification Framework: Early Stage Perspective (FLSRQF), Elsevier Procedia-Computer Science, 89, 359-368.

[16] Yadav, O.P., Singh, N., Chinnam, R.B. and Goel, P.S 2003. A fuzzy logic based approach to reliability improvement during product development. Reliability Engineering and System Safety, 80(1), 63-74

[17] Zadeh, L.A. 1989. Knowledge representation in fuzzy logic. IEEE Transactions on Knowledge and Data Engineering, 1(1), 89-100. 